\title{
Prolonged Thermal Relaxation of the Thermosetting Polymers
}

\author{
Alexander Korolev ${ }^{1, *(D)}$, Maxim Mishnev ${ }^{1, *}$, Nikolai Ivanovich Vatin ${ }^{1,2, *}$ and Anastasia Ignatova ${ }^{3, *}$ \\ 1 Department of Building Construction and Structures, South Ural State University, 454080 Chelyabinsk, Russia \\ 2 Self-Healing Structural Materials Laboratory, Peter the Great St. Petersburg Polytechnic University, \\ 195251 Saint Petersburg, Russia \\ 3 Department of Technical Mechanics, South Ural State University, 454080 Chelyabinsk, Russia \\ * Correspondence: korolev@sc74.ru or korolevas@susu.ac.ru (A.K.); mishnevmv@susu.ru (M.M.); \\ vatinni@susu.ru (N.I.V.); ignatovaav@susu.ru (A.I.); Tel.: +7-(922)-750-6508 (A.K.); +7-(999)-585-1936 (M.M.)
}

Citation: Korolev, A.; Mishnev, M.; Vatin, N.I.; Ignatova, A. Prolonged

Thermal Relaxation of the

Thermosetting Polymers. Polymers 2021, 13, 4104. https://doi.org/ $10.3390 /$ polym 13234104

Academic Editors: Gabriela

Mărginean, Vasile Cojocaru and

Doina Frunzăverde

Received: 7 October 2021

Accepted: 22 November 2021

Published: 25 November 2021

Publisher's Note: MDPI stays neutral with regard to jurisdictional claims in published maps and institutional affiliations.

Copyright: (C) 2021 by the authors. Licensee MDPI, Basel, Switzerland. This article is an open access article distributed under the terms and conditions of the Creative Commons Attribution (CC BY) license (https:/ / creativecommons.org/licenses/by/ $4.0 /)$.

\begin{abstract}
The rigidity of structures made of polymer composite materials, operated at elevated temperatures, is mainly determined by the residual rigidity of the polymer binder (which is very sensitive to elevated temperatures); therefore, the study of ways to increase the rigidity of polymer materials under heating (including prolonged heating) is relevant. In the previous research, cured thermosetting polymer structure's non-stability, especially under heating, is determined by its supramolecular structure domain's conglomerate character and the high entropy of such structures. The polymer elasticity modeling proved the significance of the entropy factor and layer (EPL) model application. The prolonged heating makes it possible to release adsorptive inter-layer bonds and volatile groups. As a result, the polymer structure is changing, and inner stress relaxation occurs due to this thermo-process, called thermo-relaxation. The present study suggests researching thermorelaxation's influence on polymers' deformability under load and heating. The research results prove the significant polymer structure modification due to thermo-relaxation, with the polymer entropy parameter decreasing, the glassing onset temperature point $(\mathrm{Tg})$ increasing by 1.3-1.7 times, and the modulus of elasticity under heating increasing by $1.5-2$ times.
\end{abstract}

Keywords: polymer; elasticity; deformability; modulus of elasticity; thermo-relaxation; glassing onset; thermal load

\section{Introduction}

According to most of the research, elasticity of thermosetting polymers under decreasing heat is a result of the following processes:

1. Polymer molecules thermo-expanding with their morphology and pack changes [1-5].

2. Inter-molecular bonds' flexibility and torsion increasing under heating [6-8].

The previous research [9] presented structural and mass changes under heating. The thermo-gravimetry proved the continuous mass loss of absolutely cured epoxy and phenolic polymers under all heating temperatures. Therefore, the processes under heating are complex and have not been researched enough.

The application of the layer model in elasticity prediction ensured the proposal of a domain-like polymer structure, which appeared due to polymerization promotion from the most dispersed reactional centers and displacement of the most volatile and unreactive fractions on the peripheral surfaces of hardening domains. The domains dominate intermolecular or van-der-Waals bonds. Domains form the border between phases of the interphase transition zone (ITZ). The ITZ is a consequence of the conglomerate type of polymer structure and is realized because of supramolecular processes during polymer glassing. Previous studies have revealed the following ITZ conditions:

1. Polymer glassing is an insular distributed process developing from reaction centers. Structures found due to this research process are globular or domain conglomer- 
ate structures, because the peripheric surface of domains has properties other than inner $[10,11]$.

2. Inter-domain bonds are molecular, so they have less energy and are more moveable under load and heating [12-15]. The energy of dissipation or entropy can determine the energy of these bonds.

3. Molecular inter-domain bonds determine the rheology of ITZ and make its character viscose or viscoelastic [16-21]. It reflects on the viscoelastic deformative properties of the overall polymer structure. ITZ is an inter-domain surface and matrix of the glassed conglomerate. Due to its matrix character, the ITZ is endless and can mass remove and create sliding surfaces for deformation under load and heating.

With temperature increases, inter-domain bonds of polymer structure lose elasticity, and polymer deformations become viscoelastic [21-24]. A curve illustrating the viscoelastic behavior of thermosetting polymers is presented, for example, in [21]. The parameter characterizing the transition from elastic to viscoelastic condition is the glassing onset temperature point, Tg. Along with heating, the mass loss of weakly bonded components occurs simultaneously, so the final structure and its parameters are changing. The stress-strain condition of the structure is changing too, which influences the thermo-relaxation process. Many researchers are dedicated to studying the thermo-relaxation of polymers [25-34] using Arrhenius, Vogel-Fulcher-Tammann (VFT), and Bässler laws, as thermodynamic equations based on free energy parameters, but most describe cycle processes with viscosity, rest deformation, and strength definition in the glassing temperature $\mathrm{Tg}$ area. In construction practice, the actuality has the polymer deformability and the influence of thermo-relaxation on it in all areas, from normal to $\mathrm{Tg}$ temperatures.

Therefore, this research explores polymers' deformability under heating prediction, where the $\mathrm{Tg}$ is an important parameter for exploiting the temperature limit. The presented research aims to determine the influence of thermo-relaxation on the polymer glassing onset temperature point and the modulus of elasticity under heating. The research object was a glassed polymer with epoxy, phenolic, and epoxy-phenolic glassed binders and similar materials.

The subject of this research is the glassed polymer modulus of elasticity under heating and its glassing onset temperature after the previous step-by-step definite temperatures of heating of polymer samples.

The research includes several objectives, as follows:

- Thermo-gravimetry and modulus of elasticity after heating of glassed polymers.

- DMA research for glassing onset temperature points before and after thermo-relaxation.

- Study of the polymer "deformation modulus-temperature" dependence before and after thermo-relaxation.

\section{Materials and Methods}

\subsection{Materials}

Table 1 presents the characteristics of thermosetting polymer materials. The thermal stability (as weight loss) and deformability were measured at elevated temperatures for these materials. The table shows the percentage by mass of components in the composition of the binder.

Table 1. Types of binders investigated.

\begin{tabular}{|c|c|c|c|c|}
\hline No. & Compound & Designation & $\begin{array}{l}\text { Thermogravimetric } \\
\text { Analysis }\end{array}$ & $\begin{array}{c}\text { Three-Point Bending Test at Elevated } \\
\text { Temperature }\end{array}$ \\
\hline 1 & $\begin{array}{l}\text { Epoxy resin (Ker } 82852.5 \%+ \\
\text { MTHPA } 44.5 \%+\text { alkofen } 3 \%)\end{array}$ & EP & + & + \\
\hline 2 & Phenolic resin (SFZ-309) 100\% & $\mathrm{PF}$ & + & + \\
\hline 3 & $\begin{array}{l}\text { Epoxy-phenolic resin (KER } 828 \text { 45\% } \\
+ \text { + SFZ-309 55\%) }\end{array}$ & EP-PF & + & + \\
\hline
\end{tabular}


The components described below were used to make the binders:

- Epoxy resin KER 828, with the following main characteristics: Epoxy Group Content (EGC) $5308 \mathrm{mmol} / \mathrm{kg}$, Epoxide Equivalent Weight (EEW) $188.5 \mathrm{~g} / \mathrm{eq}$, viscosity at $25^{\circ} \mathrm{C}$ 12.7 Pa.s, $\mathrm{HCl} 116 \mathrm{mg} / \mathrm{kg}$, and total chlorine $1011 \mathrm{mg} / \mathrm{kg}$. Manufacturer: KUMHO P\&B Chemicals, Gwangju, South Korea.

- Hardener for epoxy resin methyl tetrahydrophthalic anhydride with the following main characteristics: viscosity at $25{ }^{\circ} \mathrm{C} 63$ Pa.s, anhydride content $42.4 \%$, volatile fraction content $0.55 \%$, and free acid $0.1 \%$. Manufacturer: ASAMBLY Chemicals company Ltd., Nanjing, China.

- Alkofen (epoxy resin curing accelerator) with the following main characteristics: viscosity at $25^{\circ} \mathrm{C} 150$ Pa.s, molecular formula $\mathrm{C}_{15} \mathrm{H}_{27} \mathrm{~N}_{3} \mathrm{O}$, molecular weight 265 , and amine value $600 \mathrm{mg} \mathrm{KOH} / \mathrm{g}$. Manufacturer: Epital JSC, Moscow, Russian Federation.

- Resol phenolic resin SFRZ-309 with the following main characteristics: viscosity at $25^{\circ} \mathrm{C} 700 \mathrm{mPa} . \mathrm{s}$, not more than $20 \%(\mathrm{~m} / \mathrm{m})$ water, and not more than $20 \%(\mathrm{~m} / \mathrm{m})$ free phenol. Manufacturer: FCP "Sverdlov Plant", Dzerzhinsk, Russian Federation.

The components were mixed in the above proportions at room temperature of about $25^{\circ} \mathrm{C}$. Mixing to a homogeneous consistency was carried out mechanically with an electric drill with a mixing attachment.

Epoxy resin samples were cured at $120^{\circ} \mathrm{C}$ for $30 \mathrm{~min}$, epoxy-phenolic binder was cured at $70{ }^{\circ} \mathrm{C}$ for $120 \mathrm{~min}$, then $120^{\circ} \mathrm{C}$ for $60 \mathrm{~min}$, and phenolic resin was cured at $70{ }^{\circ} \mathrm{C}$ for $90 \mathrm{~min}$, then at $120^{\circ} \mathrm{C}$ for $60 \mathrm{~min}$. After curing, all samples were kept at $150{ }^{\circ} \mathrm{C}$ for $12 \mathrm{~h}$.

The samples were cured in silicone molds in the form of plates, from which bar samples were subsequently cut. A general view of a silicone mold with curing binders for making samples and cured samples of binders is shown in Figure 1.
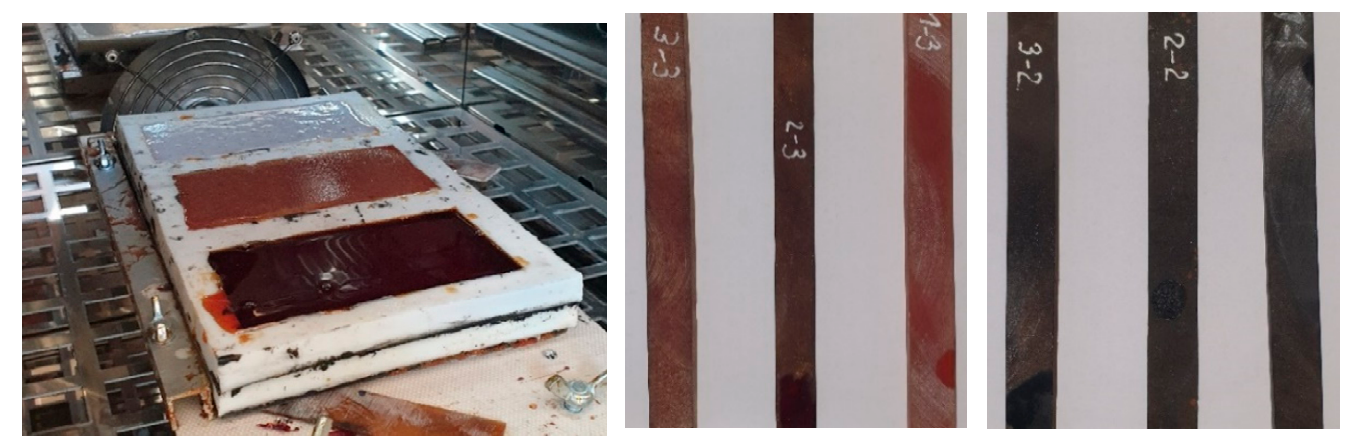

Figure 1. Samples in the curing process and after cutting from cured plates.

\subsection{Methods}

After curing, bar samples of cured polymer binders were exposed to prolonged exposure at elevated temperatures. In this case, one of the samples of each type was a control one, which was not exposed to aging at elevated temperatures. Before the start of long-term storage, the initial glass transition temperature was determined for all samples using DMA, and the elastic modulus was determined using three-point bending at room temperature $\left(22-25^{\circ} \mathrm{C}\right)$, which will hereinafter be referred to as the "cold" modulus of elasticity, and at elevated temperatures.

Long-term exposure of samples at elevated temperatures was carried out according to the following program: $189 \mathrm{~h}$ at $160^{\circ} \mathrm{C}, 182 \mathrm{~h}$ at $190^{\circ} \mathrm{C}$, and $429 \mathrm{~h}$ at $220{ }^{\circ} \mathrm{C}$. Periodically (after 6-48 h), the samples were cooled at a rate of about $1{ }^{\circ} \mathrm{C}$ per minute up to $50{ }^{\circ} \mathrm{C}$, were taken out of the laboratory oven, weighed, and after each weighing (TG analysis), their elastic modulus was determined at room temperature $\left(22-25^{\circ} \mathrm{C}\right)$.

After the end of long-term holding at elevated temperatures, the glass transition temperatures were determined for each sample using DMA, and the curves of the dependence of the elastic modulus in bending on temperature were plotted. The dynamic mechanical 
analysis (DMA) was performed using a NETZCSH DMA 242C analyzer (Erich NETZSCH GmbH \& Co. Holding KG, Gebrüder-Netzsch-Straße 19, Germany).

During the tests, the dynamic modulus of elasticity, the modulus of viscosity, and the tangent of the angle of mechanical losses were determined. When the polymer reaches the glass transition temperature $(\mathrm{Tg})$, a significant drop in the dynamic modulus of elasticity is observed. Following GOST R 57739-2017 [35], the glass transition temperature was determined as the intersection of two tangents to the dynamic modulus of the elasticity graph.

Table 2 shows the sizes of the samples tested. The samples were subjected to sinusoidal force action according to the three-point bending scheme at a span of $20 \mathrm{~mm}$ to determine the viscoelastic characteristics and glass transition temperature. The frequency was $5 \mathrm{~Hz}$, the value of the static component of the load was $0.72 \mathrm{~N}$, and the dynamic component of the load was $0.4 \mathrm{~N}$. The experiments were carried out in the temperature range of 25-130/ $140{ }^{\circ} \mathrm{C}$ at a rate of $1^{\circ} \mathrm{C} / \mathrm{min}$. For sample No. 3, tests were carried out in the temperature range from 25 to $300{ }^{\circ} \mathrm{C}$.

Table 2. Sample sizes for DMA.

\begin{tabular}{cccc}
\hline No. & Compound & Width, $\mathbf{~ m m}$ & Thickness, $\mathbf{m m}$ \\
\hline \multirow{2}{*}{1} & Epoxy resin (Ker 828 52.5\% + & 8.72 & 3.48 \\
2 & MTHPA 44.5\% + alkofen 3\%) & 5.95 & 2.8 \\
3 & Phenolic resin (SFZ-309) 100\% & 7.03 & 2.95 \\
\hline
\end{tabular}

As a result, the values of the glass transition temperatures were determined for the samples of polymer binders before and after prolonged exposure at elevated temperatures.

Along with modern high-precision methods of mechanical testing of polymer materials and composites (for example, those described in [36]), three-point bending tests (for example, described in [37]), which have long been known but have not lost their relevance due to the simplicity of the equipment used, are widely used. The elastic modulus at three-point bending was the main mechanical characteristic for estimating the stiffness of polymers at normal and elevated temperatures.

Three-point bending tests of polymer samples were carried out on a Tinius Olsen h100ku testing machine (Tinius Olsen GmbH, Goethestr. 7b, 86161 Augsburg, Germany) in a specially made small-sized chamber, which provides heating and maintains the temperature up to $300^{\circ} \mathrm{C}$.

According to the producer's data for a Tinius Olsen h100ku machine, the load accuracy was $\pm 0.5 \%$ in the range of $0.2-100 \%$ of the installed force sensor $(100 \mathrm{kN})$. The resolution of measuring the crosshead movement was $0.1 \mathrm{~mm}$, with an error of up to $0.01 \mathrm{~mm}$. The sample center point displacement under the load was monitored by a mechanical dial gauge mounted on the bottom of the small-sized test chamber. This monitoring was aimed at excluding the machine compliance influence. The difference between the displacement readings along the traverse and the dial gauge did not exceed $2 \%$.

Three-point bending tests determined the cured sample deformation modulus at temperatures from 25 to $230{ }^{\circ} \mathrm{C}$. The tests were carried out following Russian State Standard GOST 25.604-82 [36]. The experimental values of elasticity modulus at the bending of the samples were determined at a $2 \mathrm{~mm} / \mathrm{min}$ loading rate. The determination of the elasticity modulus was carried out under loading with two load steps.

When determining the elastic modulus in bending, the samples were preliminarily loaded with a concentrated force to the level of normal stresses of 1.2 MPa. Further, loading was carried out, and the determination of the elastic modulus was carried out at the range of normal stresses of 1.2-3.2 MPa.

The samples were preliminarily held at elevated temperatures until they were completely warmed up to the test temperature. The temperature during the tests was maintained by a thermostat and controlled by two thermocouples. One thermocouple measured 
the temperature on the surface of the bent specimen. The second thermocouple measured the temperature inside the control specimen, located next to the test specimen. The installation diagram is shown in Figure 2.

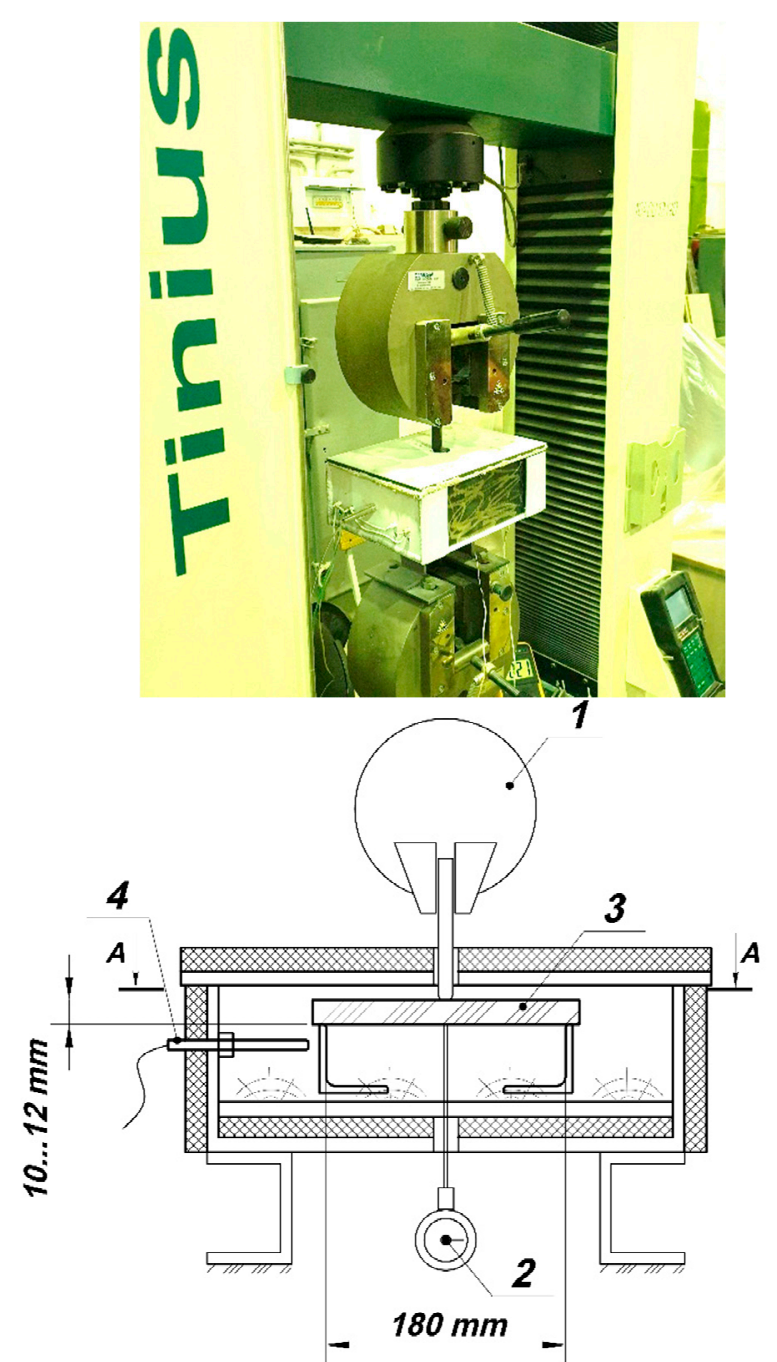

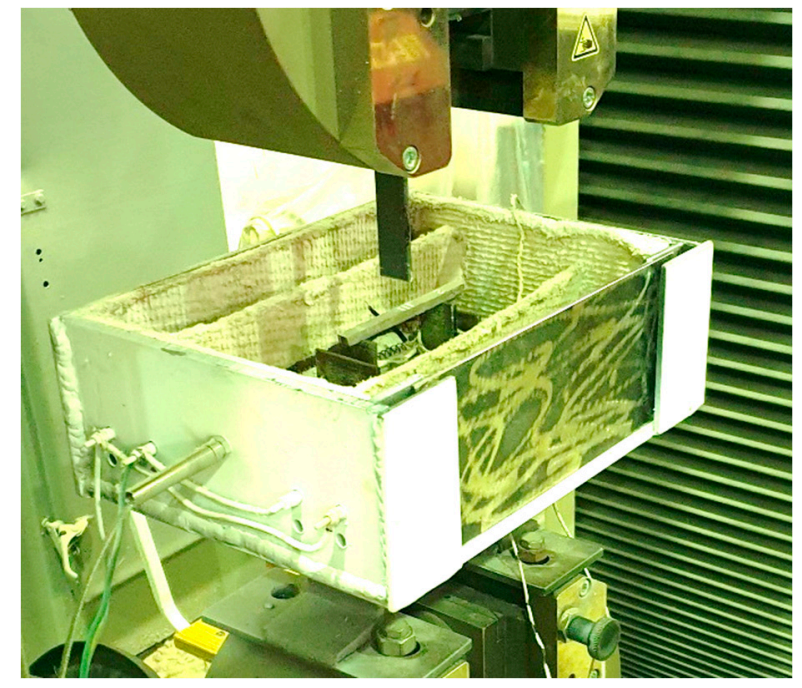

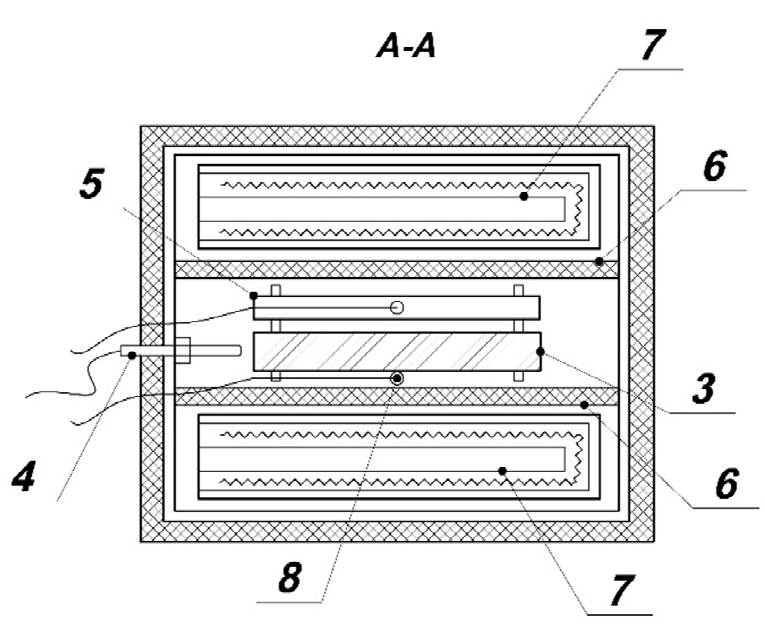

Figure 2. Heating three-point bending test rig: 1-Testing machine, 2-Indicator, 3-Bend specimen, 4-Thermocouple of a thermostat, 5-Thermocouple specimen, 6-Baffle, 7-Heater, 8-Thermocouple.

\section{Results and Discussion}

\subsection{Polymer Mass Lost under Heating and Modulus of Elasticity after Heating Research}

Empirical dependences of epoxy, epoxy-phenolic and phenolic polymers' mass lost upon exposure at elevated temperatures are shown in Figure 3. Indexes 1 and 2 are the experimental repetition with the same compounds. It is shown that at each stage of heating, significant mass loss appears. The total mass lost can achieve $4-13 \%$, and the most mass lost begins developing at $160^{\circ} \mathrm{C}$. The prolonged heating was performed in three stages, at 160,190 , and $220^{\circ} \mathrm{C}$. The mass loss continued at each stage until constant mass. With the transition to the next increasing temperature stage, the mass loss begins again at the next constant mass. This effect shows that the polymer structure keeps many weakly bonded volatile groups with different bond strengths. Since most of the mass loss is developing up to $220^{\circ} \mathrm{C}$, it is proposed that these groups have to dominate adsorptive or van-der-Waals bonds. Therefore, those volatile groups sublimate at each stage if heat energy is enough to destroy their adsorptive bonds. The duration of mass loss is related to the difficulty of 
mass removal from the inner to the outer space of the polymer volume. In this case, the thermo-relaxation process is realized, and polymer structure entropy decreases.

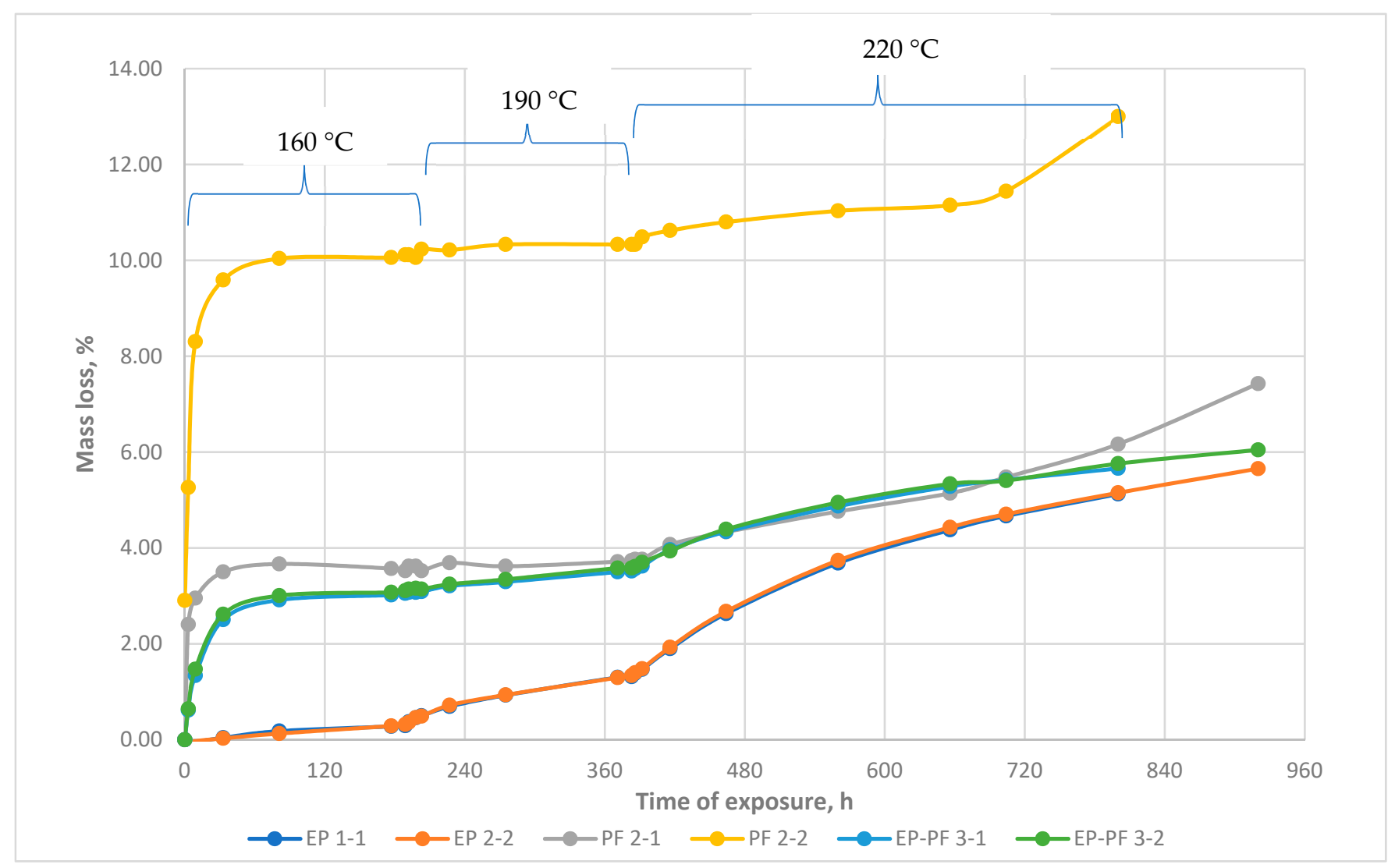

Figure 3. Character dependence of polymer mass loss of polymer samples on temperature: epoxy resin (EP), phenolic resin (PF), and epoxy-phenolic (EP-PF).

From this point of view, several volatile polymer groups between elastic domains define the viscoelasticity of the polymer under load and heating, particularly the glassing onset temperature point. It is proposed that with volatile groups decreasing after heating, the width of ITZ decreases too, and the strength of inter-domain bonds, elasticity, and Tg has to increase significantly. It is suggested by empirical dependences of epoxy, epoxyphenolic, and phenolic polymers' elasticity at normal temperature modulus after prolonged exposure to high temperatures (Figure 4).

In one of the samples of pure phenolic resin (PF 2-2), at the initial stage of thermal relaxation, the weight loss was more intense. The weight loss at this stage was probably mainly due to the evaporation of water that forms during curing. However, in the further stages, the intensity of weight loss leveled off for both samples. If we do not consider the initial section, then in the further stages in both samples, the process of weight loss during prolonged storage had a comparable intensity.

Additionally, the phenolic binder samples at a certain moment of exposure at a temperature of $220^{\circ} \mathrm{C}$ simultaneously began to lose weight more intensively than before, while the temperature did not change (see Figure 3, PF 2-1 and PF 2-2 after $720 \mathrm{~h}$ of exposure). It is also noteworthy that after a change in the intensity of mass loss, the elastic modulus of both exposed samples (see Figure 5 after $720 \mathrm{~h}$ of exposure) also decreased, while the modulus of elasticity of the reference sample did not change. This suggests that in the structure of phenolic resin as a result of prolonged exposure to temperature, there was an accumulation of certain changes, which manifested themselves in the form of an increase in the intensity of weight loss and a decrease in hardness, without increasing the external temperature. 


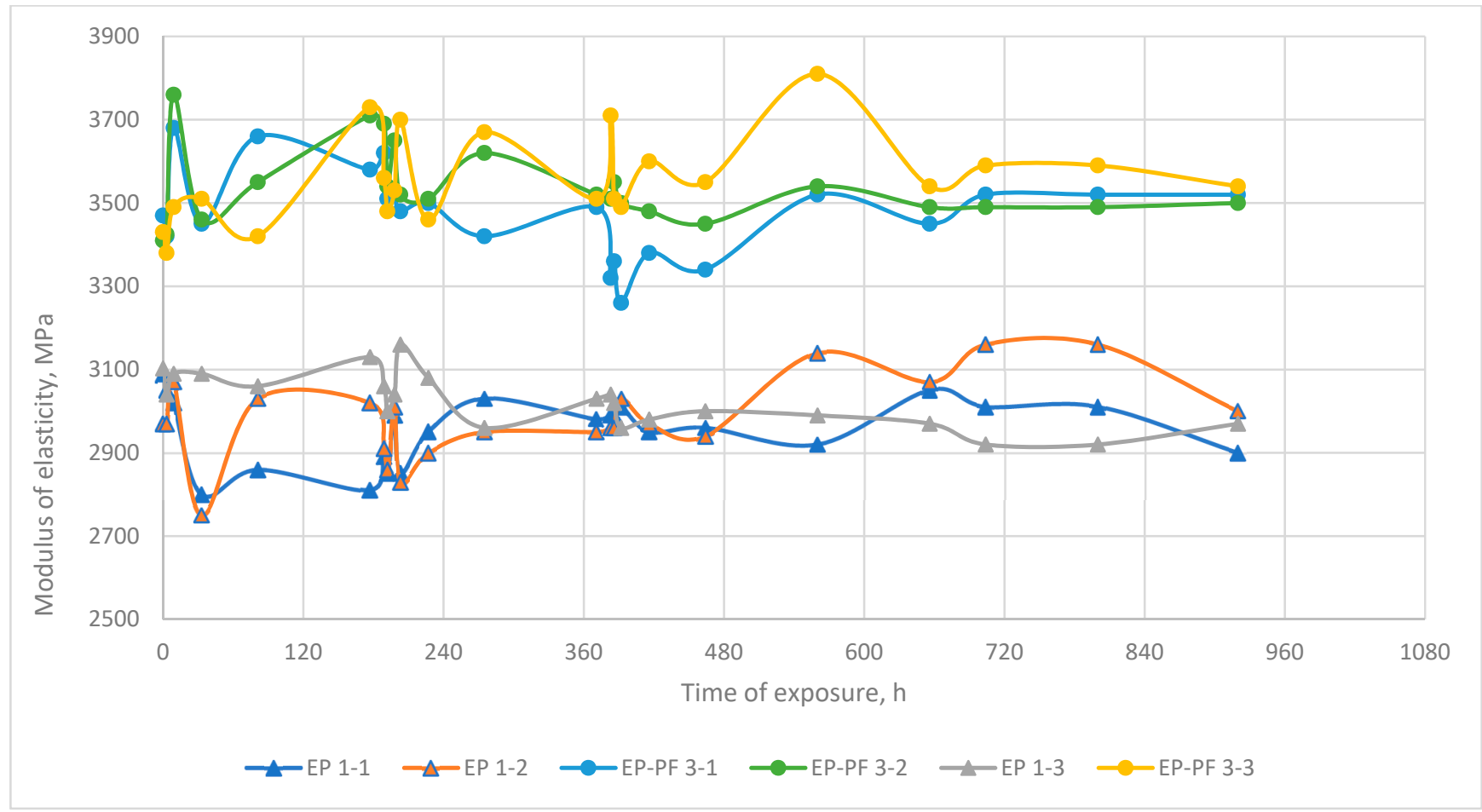

Figure 4. Character dependence of polymer elasticity (cold) modulus after exposure at elevated temperatures: EP-epoxy resin, EP-PF-epoxy-phenolic. EP 1-1, 1-2, EP-PF 3-1, 3-2: exposure at elevated temperature, EP 1-3, EP-PF 3-3: not exposed at elevated temperature.

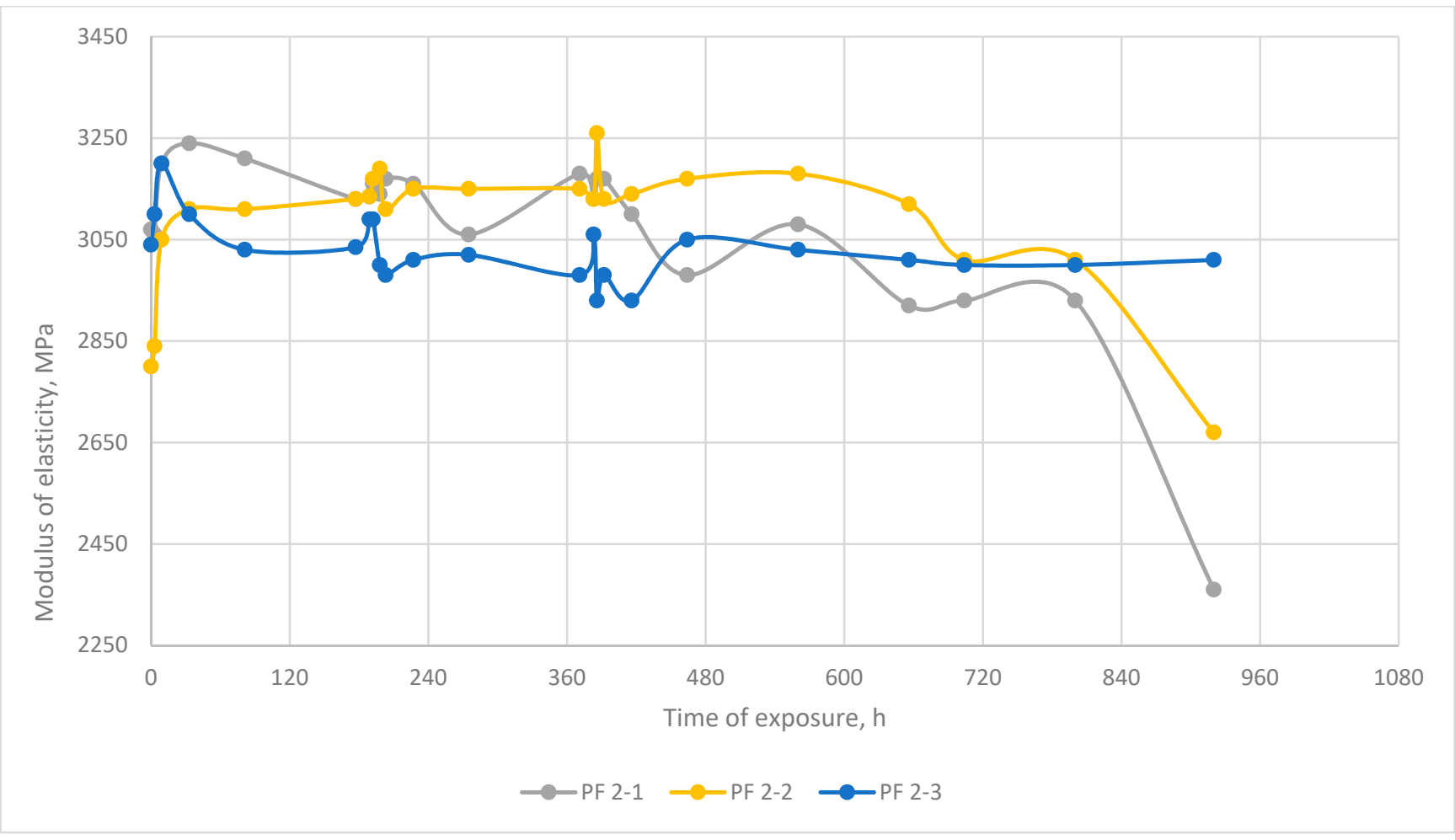

Figure 5. Character dependence of phenolic resin elasticity (cold) modulus after exposure at elevated temperatures. PF 2-1, PF 2-2: exposure at elevated temperature, PF 2-3: not exposed at elevated temperature.

Empirical data prove that the normal temperature elasticity modulus of polymers after thermo-relaxation changes wavily, depending on temperature and time of exposure. 
It demonstrates that exposure under heating modifies the polymer structure, and the thermo-relaxation process is realized. Ultimately, however, the difference between the normal temperature modulus of elasticity before and after exposure does not exceed $10 \%$, so it cannot be said that the normal temperature modulus of elasticity changed significantly after exposure.

Another situation arises when considering the glass transition temperature and elastic modulus at elevated temperatures (high-temperature elastic modulus).

\subsection{Polymers before and after Thermo-Relaxation DMA}

The results of the DMA are presented in Figures 6 and 7.
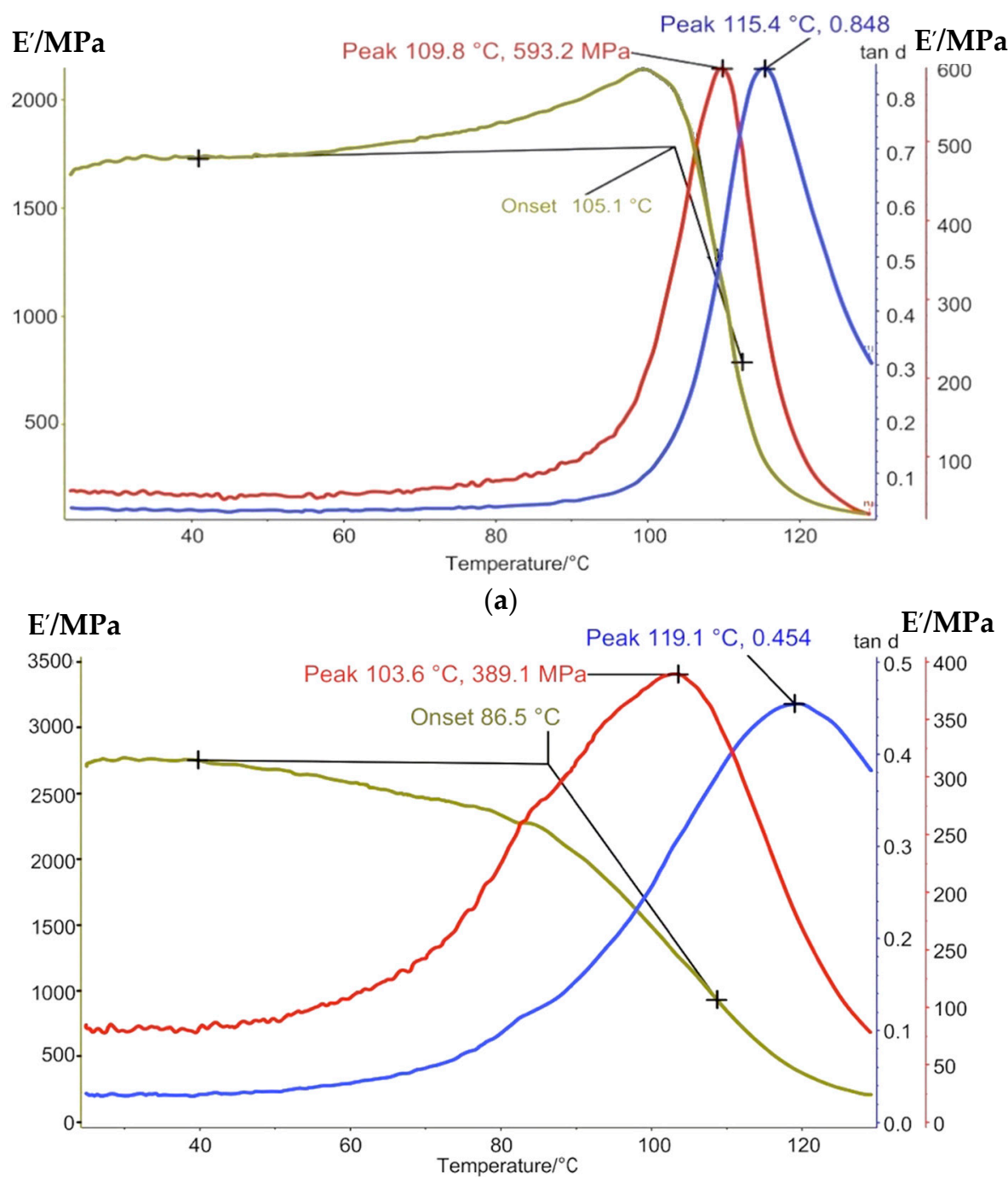

(b)

Figure 6. Cont. 


\section{$\mathbf{E}^{\prime} / \mathrm{MPa}$}

$\mathbf{E}^{\prime} / \mathrm{MPa}$

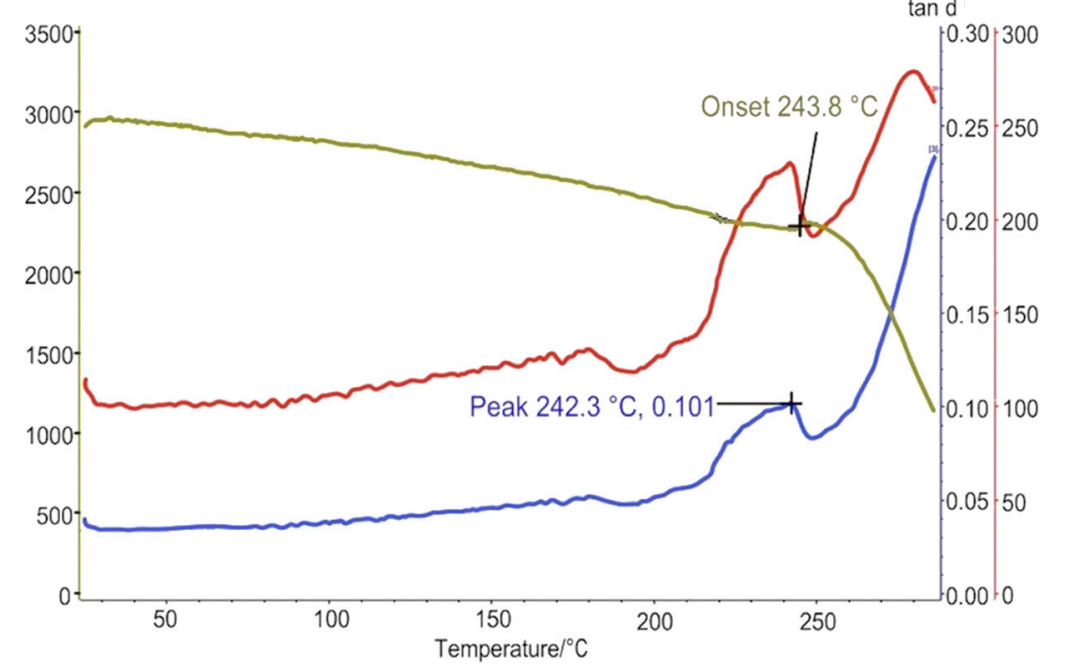

(c)

Figure 6. DMA curves of glassed polymers before thermo-relaxation: (a) epoxy resin, (b) epoxyphenolic resin, and (c) phenolic resin.

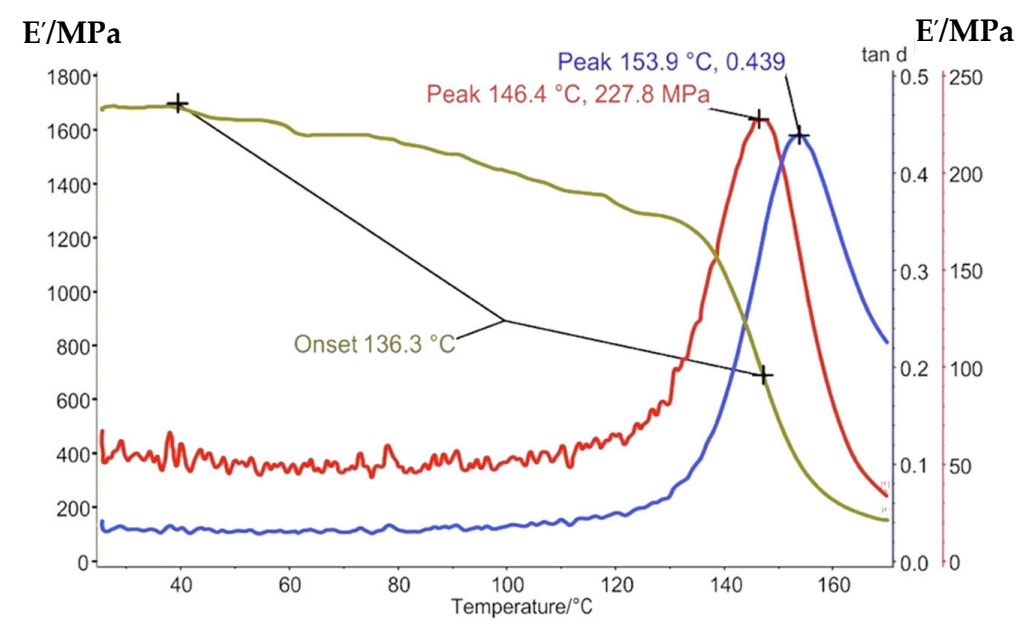

(a)

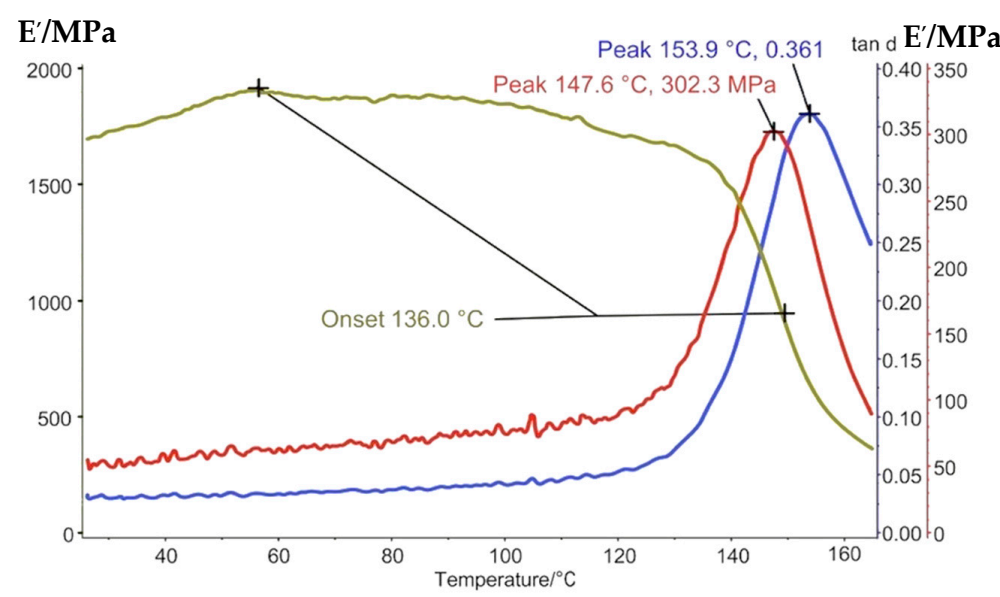

(b)

Figure 7. DMA curves of glassed polymers before thermo-relaxation: (a) epoxy resin and (b) epoxyphenolic resin. 
As it can be seen from the DMA curves, a significant change as a result of thermorelaxation is developing. Not only does Tg increase by 1.3-1.7 times, but the straight/rest dynamic modulus ratio ( $\tan \mathrm{d}$ ) at the low peak decreased by 1.5 times, so the deformation modulus increases after $\mathrm{Tg}$. It proves that the thermo-relaxation influences the polymer elasticity proposal.

\subsection{Testing the Polymer Elasticity Modulus concerning Temperature and Entropy Factor after Thermo-Relaxation}

The results of the elasticity modulus under heating tested before and after exposure at elevated temperatures are presented in Figures 8-10.

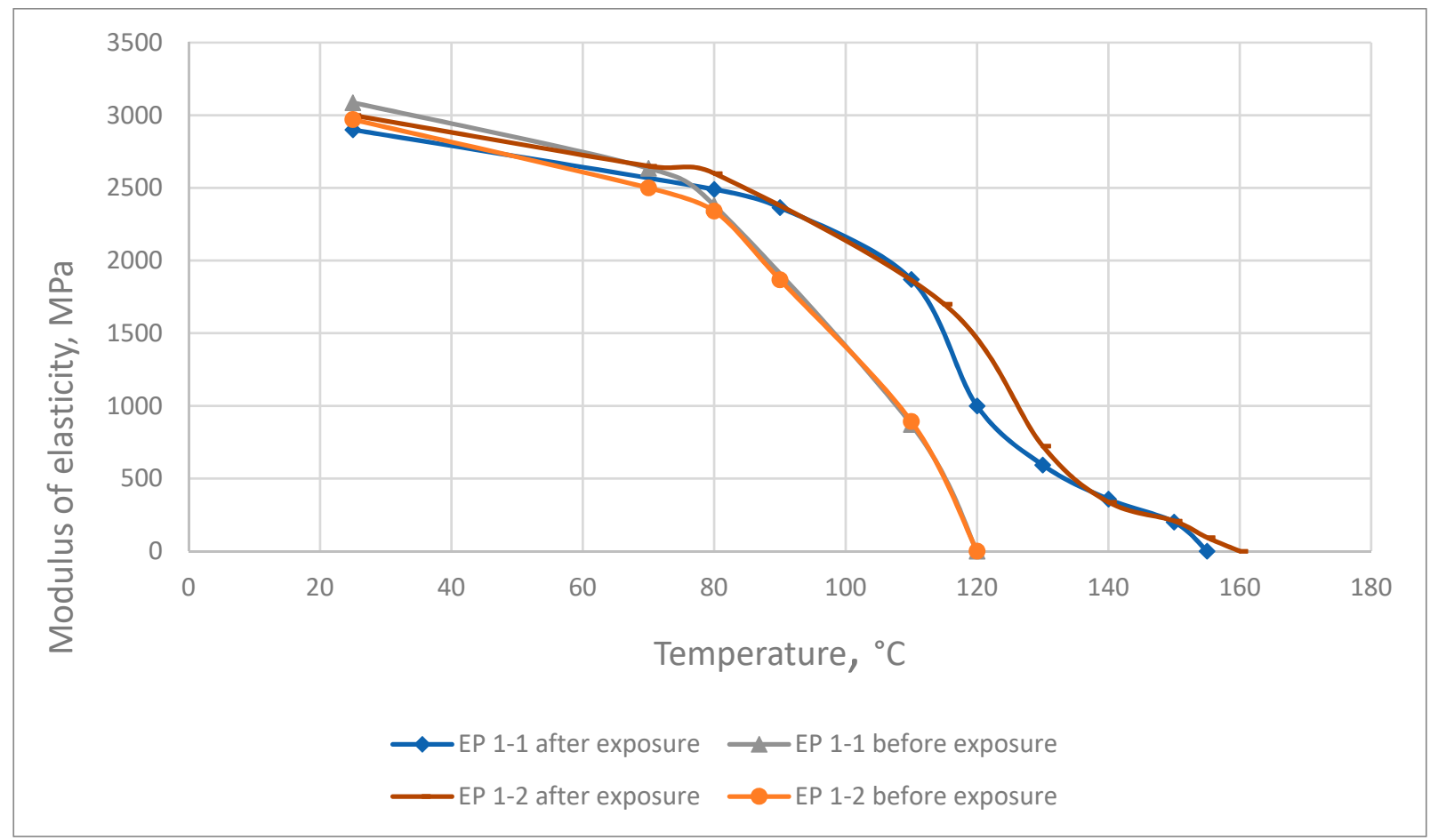

Figure 8. Dependence of the epoxy resin elastic modulus on temperature before and after long exposure at elevated temperatures.

The thermo-relaxation increases the polymers' elasticity under heating. According to the DMA results, the breakpoint to viscoelasticity increases by up to more than 1.3 times.

According to the layer model (EPL model) [9], the previously proposed and tested modulus of deformation dependence on temperature can be calculated as:

$$
\mathrm{E}_{\mathrm{T}}=\frac{k_{p l} \mathrm{E}_{0}}{1-\mathrm{n}_{\mathrm{T}}\left(1-k_{p l}\right)}
$$

where $\mathrm{n}_{\mathrm{T}}$ is a fraction of elastic bonds in all bonds' amount, and $k_{p l}$ is the plastic bonds' deformability modulus to elastic bonds' elasticity modulus ratio (deformability ratio).

Based on previous temperature-changing polymer structure research results, the deformability ratio of the adsorptive bond is related to temperature by the entropy equation:

$$
k_{p l}=1-S * \ln \frac{\mathrm{T}_{\mathrm{s}}}{\mathrm{T}_{0}}
$$

where $S(\mathrm{~J} / \mathrm{J})$ is the coefficient of the bond entropy equal to the relation between entropy and potential energy of the elastic bond at standard temperature, and $S$ and $\mathrm{n}_{\mathrm{T}}$ are correlative parameters with physical essence in this research stage. 


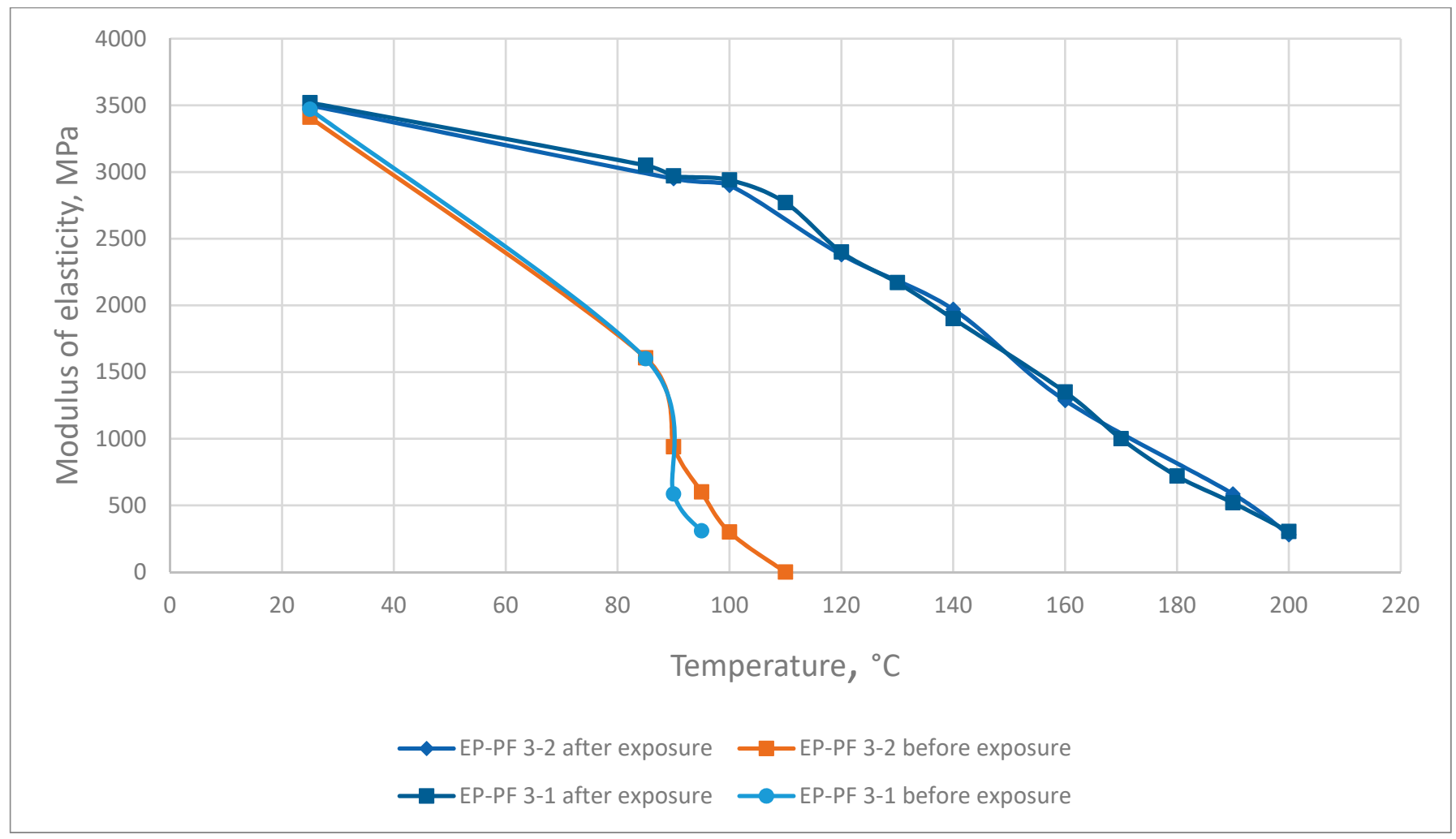

Figure 9. Dependence of the epoxy-phenolic resin elastic modulus on temperature before and after long exposure at elevated temperatures.

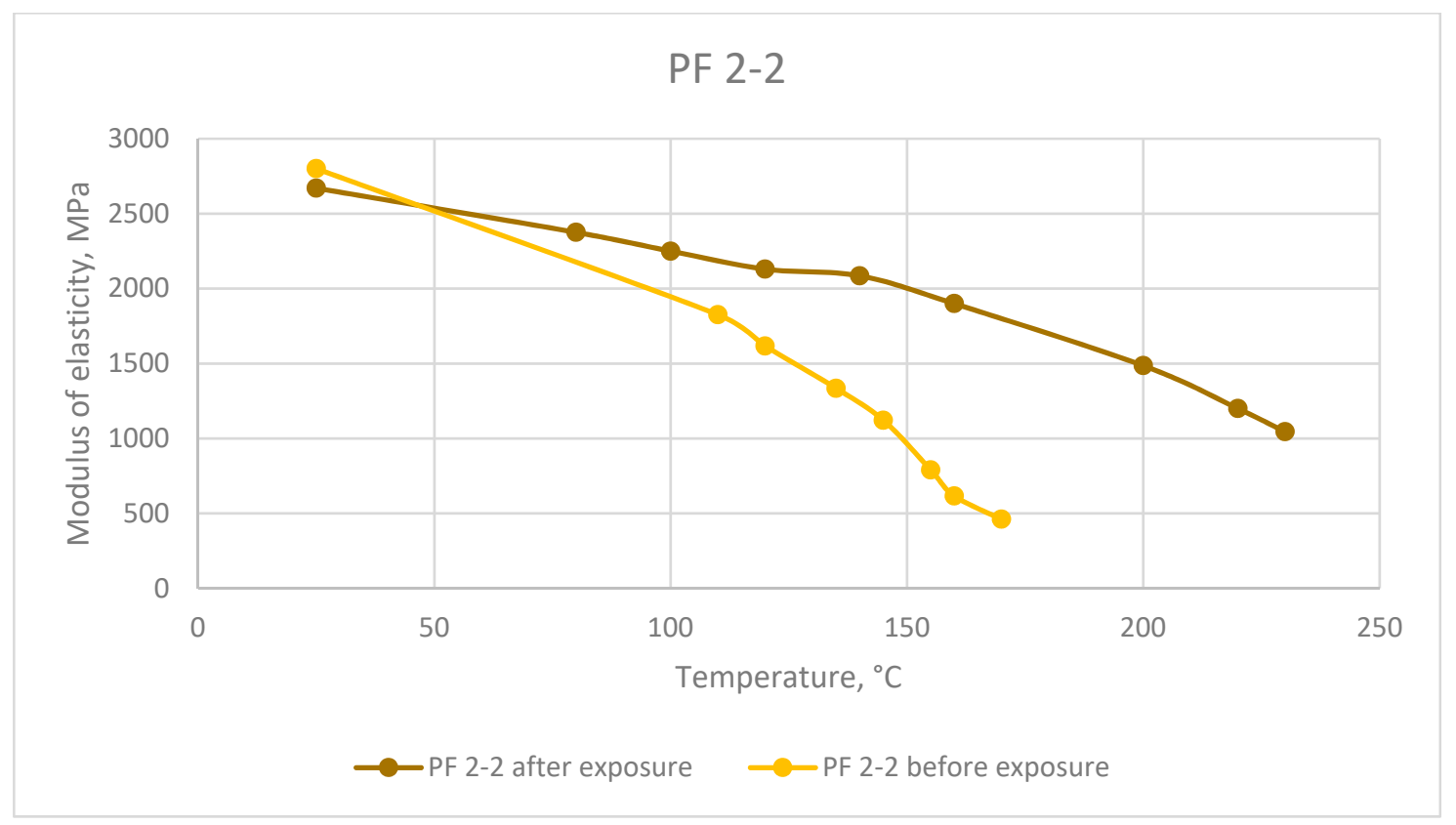

Figure 10. Dependence of the phenolic resin elastic modulus on temperature before and after long exposure at elevated temperatures.

Before the thermo-relaxation, the entropy and structure coefficients are as follows: For epoxy resin composition, the equation is:

$$
k_{\text {pl-epox }}=1-3.6 \ln \frac{273+\mathrm{t}_{\mathrm{s}}}{298}
$$




$$
\mathrm{E}_{\mathrm{T}}=\frac{k_{p l-e p o x} \mathrm{E}_{0}}{1-0.77\left(1-k_{p l-e p o x}\right)}
$$

For phenolic resin composition:

$$
\begin{aligned}
& k_{p l-f e n o l}=1-2.5 \ln \frac{273+\mathrm{t}_{\mathrm{s}}}{298} \\
& \mathrm{E}_{\mathrm{T}}=\frac{k_{p l-f e n o l} \mathrm{E}_{0}}{1-0.65\left(1-k_{p l-f e n o l}\right)}
\end{aligned}
$$

For epoxy-phenolic resin composition:

$$
\begin{aligned}
& k_{p l-e p-f e n}=1-4.7 \ln \frac{273+\mathrm{t}_{\mathrm{s}}}{298} \\
& \mathrm{E}_{\mathrm{T}}=\frac{k_{p l-e p-f e n} \mathrm{E}_{0}}{1-0.8\left(1-k_{p l-e p-f e n}\right)}
\end{aligned}
$$

After the thermo-relaxation, the entropy and structure coefficients are as follows: For epoxy resin composition, the equation is:

$$
\begin{aligned}
& k_{p l-e p o x}=1-2.8 \ln \frac{273+\mathrm{t}_{\mathrm{s}}}{298} \\
& \mathrm{E}_{\mathrm{T}}=\frac{k_{p l-e p o x} \mathrm{E}_{0}}{1-0.77\left(1-k_{p l-e p o x}\right)}
\end{aligned}
$$

For phenolic resin composition:

$$
\begin{aligned}
& k_{p l-\text { fenol }}=1-1.6 \ln \frac{273+\mathrm{t}_{\mathrm{s}}}{298} \\
& \mathrm{E}_{\mathrm{T}}=\frac{k_{p l-\text { fenol }} \mathrm{E}_{0}}{1-0.65\left(1-k_{p l-f e n o l}\right)}
\end{aligned}
$$

For epoxy-phenolic resin composition:

$$
\begin{aligned}
& k_{p l-e p-f e n}=1-2.3 \ln \frac{273+\mathrm{t}_{\mathrm{s}}}{298} \\
& \mathrm{E}_{\mathrm{T}}=\frac{k_{p l-e p-f e n} \mathrm{E}_{0}}{1-0.8\left(1-k_{p l-e p-f e n}\right)}
\end{aligned}
$$

Tables $3-5$ present the data of the actual and calculated deformation modulus under heating before and after thermo-relaxation.

The average derivation of the elasticity modulus under heating calculation is just $2.6 \%$. It proves that layer modeling included the highest accuracy and applicability entropy factor. Models' analysis after thermo-relaxation showed that the entropy coefficient decreased by 1.5-2 times, but the structure layer coefficient remained constant. This means that the thermo-relaxation result is the reduction of the structure entropy and elasticity under heating, and the increase of the glass point. 
Table 3. Comparative actual and calculated data for epoxy modulus of deformation under heating before and after thermo-relaxation.

\begin{tabular}{|c|c|c|c|c|c|c|}
\hline Compound & Temperature, ${ }^{\circ} \mathrm{C}$ & $\begin{array}{l}\mathrm{E}_{\text {fact }} \\
\mathrm{MPa}\end{array}$ & $\begin{array}{l}\mathrm{S}, \\
\mathrm{J} / \mathrm{J}\end{array}$ & $k_{p l}$ & $\begin{array}{l}\mathrm{E}_{\text {calc }} \\
\mathrm{MPa}\end{array}$ & $\stackrel{\%}{\%}$ Derivation \\
\hline \multirow{5}{*}{$\begin{array}{l}\text { Epoxy before } \\
\text { thermo- relaxation }\end{array}$} & 25 & 3028 & \multirow{5}{*}{3.6} & 1.000 & - & - \\
\hline & 70 & 2567 & & 0.494 & 2450 & -4.6 \\
\hline & 80 & 2360 & & 0.390 & 2227 & -5.6 \\
\hline & 90 & 1868 & & 0.290 & 1899 & 1.7 \\
\hline & 110 & 893 & & 0.097 & 960 & 7.5 \\
\hline \multirow{10}{*}{$\begin{array}{l}\text { Epoxy after } \\
\text { thermo- relaxation }\end{array}$} & 25 & 2950 & \multirow{10}{*}{2.8} & 1.000 & - & \\
\hline & 70 & 2650 & & 0.606 & 2610 & -1.5 \\
\hline & 80 & 2600 & & 0.523 & 2443 & -6.0 \\
\hline & 90 & 2365 & & 0.448 & 2259 & -4.4 \\
\hline & 110 & 1870 & & 0.297 & 1878 & 0.4 \\
\hline & 115 & 1700 & & 0.261 & 1817 & 6.9 \\
\hline & 120 & 1000 & & 0.225 & 1618 & 61.8 \\
\hline & 130 & 724 & & 0.154 & 1307 & 80 \\
\hline & 140 & 338 & & 0.086 & 858 & 153 \\
\hline & 150 & 208 & & 0.019 & 231 & 6.3 \\
\hline
\end{tabular}

Table 4. Comparative actual and calculated data for phenolic modulus of deformation under heating before and after thermo-relaxation.

\begin{tabular}{|c|c|c|c|c|c|c|}
\hline Compound & Temperature, ${ }^{\circ} \mathrm{C}$ & $\begin{array}{l}\mathrm{E}_{\text {fact }} \\
\mathrm{MPa}\end{array}$ & $\begin{array}{l}\mathrm{S}, \\
\mathrm{J} / \mathrm{J}\end{array}$ & $k_{p l}$ & $\begin{array}{l}\mathrm{E}_{\text {calcr }} \\
\mathrm{MPa}\end{array}$ & $\begin{array}{c}\% \\
\text { Derivation }\end{array}$ \\
\hline \multirow{8}{*}{$\begin{array}{l}\text { Phenolic before } \\
\text { thermo-relaxation }\end{array}$} & 25 & 2935 & \multirow{8}{*}{2.5} & 1 & - & - \\
\hline & 110 & 1823 & & 0.372 & 1846 & 1.3 \\
\hline & 120 & 1678 & & 0.308 & 1644 & 2.0 \\
\hline & 135 & 1354 & & 0.214 & 1286 & -5.0 \\
\hline & 145 & 1030 & & 0.154 & 1004 & -2.5 \\
\hline & 155 & 672 & & 0.095 & 676 & 0.6 \\
\hline & 160 & 471 & & 0.065 & 491 & 4.2 \\
\hline & 170 & 462 & & 0.009 & 74 & -84 \\
\hline \multirow{9}{*}{$\begin{array}{l}\text { Phenolic after } \\
\text { thermo- relaxation }\end{array}$} & 25 & 2515 & \multirow{9}{*}{1.6} & 1 & - & - \\
\hline & 80 & 2375 & & 0.729 & 2362 & -0.5 \\
\hline & 100 & 2250 & & 0.641 & 2232 & -1.2 \\
\hline & 120 & 2130 & & 0.557 & 2089 & -1.9 \\
\hline & 140 & 2085 & & 0.478 & 1931 & -7.3 \\
\hline & 160 & 1900 & & 0.402 & 1756 & -7.5 \\
\hline & 200 & 1486 & & 0.261 & 1340 & -9.8 \\
\hline & 220 & 1200 & & 0.210 & 1155 & -3.8 \\
\hline & 230 & 1045 & & 0.178 & 1022 & -2.2 \\
\hline
\end{tabular}

Table 5. Comparative actual and calculated data for epoxy-phenolic modulus of deformation under heating before and after thermo-relaxation.

\begin{tabular}{|c|c|c|c|c|c|c|}
\hline Compound & Temperature, ${ }^{\circ} \mathrm{C}$ & $\begin{array}{l}\mathrm{E}_{\text {fact }} \\
\mathrm{MPa}\end{array}$ & $\begin{array}{l}\mathrm{S}, \\
\mathrm{J} / \mathrm{J}\end{array}$ & $k_{p l}$ & $\begin{array}{l}\mathrm{E}_{\text {calc }} \\
\mathrm{MPa}\end{array}$ & $\stackrel{\%}{\%}$ Derivation \\
\hline & 25 & 3440 & & 1 & - & - \\
\hline Epoxy-phenolic & 85 & 1603 & & 0.138 & 1528 & -4.7 \\
\hline before & 90 & 763 & 4.7 & 0.072 & 968 & 26.8 \\
\hline \multirow[t]{5}{*}{ thermo-relaxation } & 95 & 455 & & 0.008 & 139 & -69 \\
\hline & 100 & 300 & & - & - & - \\
\hline & 25 & 3510 & & 1 & - & - \\
\hline & 85 & 3050 & & 0.578 & 3071 & 0.7 \\
\hline & 90 & 2960 & & 0.546 & 3010 & 1.7 \\
\hline Epoxy-phenolic & 100 & 2920 & & 0.483 & 2887 & -0.8 \\
\hline after & 110 & 2770 & 2.3 & 0.423 & 2765 & -0.2 \\
\hline \multirow{4}{*}{ thermo-relaxation } & 120 & 2390 & & 0.364 & 2420 & 1.2 \\
\hline & 130 & 2170 & & 0.305 & 2190 & 0.9 \\
\hline & 140 & 1935 & & 0.249 & 1580 & -18.3 \\
\hline & 160 & 1320 & & 0.141 & 1147 & -13.1 \\
\hline
\end{tabular}




\section{Conclusions}

As a result of this analytical and experimental study, a significant modification of polymer structure after prolonged heating was determined. The modification was determined by a significant change of the Tg and deformation DMA modulus. After a successful layer model of polymers under load and prolonged heating elasticity prediction testing, the entropy before and after prolonged heating was determined. The results proved that entropy of the polymer structure after prolonged heating was significantly reduced, by 1.5-2 times. It points out that under prolonged heating under temperatures of more than the $\mathrm{Tg}$, the polymer thermo-relaxation was realized.

The high effectiveness of the thermo-relaxation method for polymers under an increased heating elasticity modulus was proven. Thermo-relaxation, realized as long-term secondary heating of polymer samples, significantly improved polymers' properties and structure, such as:

1. Volatile fractions' mass loss in the range of $5-10 \%$.

2. The glassing onset point increased by 1.3-1.7 times.

3. The normal temperature modulus of elasticity in bending after prolonged exposure at elevated temperatures did not change significantly. In contrast, the moduli of elasticity at high temperatures for all types of binders increased by several times.

This method can be used in practice if the first heating of structures by the recommended curves is realized.

The original layer-bonded model (EPL model) with thermodynamic parameters has been proposed and proven in the calculation of polymers' deformation modulus depending on the temperature under heating in a normal to $\mathrm{Tg}$ temperature range for all kinds of thermosetting polymers. Application of this model can be useful in calculating stresses in heated polymer-reinforced structures and developing methods of increasing heat resistance for polymer composites.

Author Contributions: Conceptualization, A.K.; methodology, M.M. and A.I.; validation, N.I.V.; formal analysis, A.K.; investigation, M.M. and A.I.; resources, M.M.; data curation, N.I.V.; writingoriginal draft preparation, A.K.; writing—review and editing, N.I.V.; visualization, M.M.; supervision, M.M.; project administration, A.K. All authors have read and agreed to the published version of the manuscript.

Funding: The research was funded by RFBR and Chelyabinsk Region, project number 20-48-740021.

Institutional Review Board Statement: Not applicable.

Informed Consent Statement: Not applicable.

Data Availability Statement: The data presented in this study are available on request from the corresponding author.

Conflicts of Interest: The authors declare no conflict of interest. The funders had no role in the design of the study; in the collection, analyses, or interpretation of data; in the writing of the manuscript, or in the decision to publish the results.

\section{References}

1. Slutsker, A.I.; Sanphirova, T.P.; Yastrebinskii, A.A.; Kuksenko, V.S. Structure and reversible deformability of oriented crystallizing polymers. J. Polym. Sci. Part C Polym. Symp. 1967, 16, 4093-4101. [CrossRef]

2. Flory, P.J.; Erman, B. Theory of elasticity of polymer networks. 3. Macromolecules 1982, 15, 800-806. [CrossRef]

3. Dill, K.A.; Bromberg, S.; Stigter, D. Polymer Elasticity \& Collapse. In Molecular Driving Forces; Garland Science: New York, NY, USA, 2018; pp. 659-684. [CrossRef]

4. Lomakin, V.A.; Ogibalov, P.M.; Teters, G.A. Problems of the theory of deformation of polymeric materials. Polym. Mech. 1972, 8, 377-385. [CrossRef]

5. Vashisth, A.; Ashraf, C.; Bakis, C.E.; van Duin, A.C.T. Effect of chemical structure on thermo-mechanical properties of epoxy polymers: Comparison of accelerated ReaxFF simulations and experiments. Polymer 2018, 158, 354-363. [CrossRef]

6. Chan, C.H.; Chia, C.H.; Thomas, S. Physical Chemistry of Macromolecules: Macro to Nanoscales; Apple Academic Press: Palm Bay, FL, USA, 2014. 
7. Kuperman, A.M.; Turusov, R.A.; Gorenberg, A.Y. Study of elastic and strength properties of hybrid and gradient polymer composites. Compos. Mech. Comput. Appl. 2010, 1, 361-373. [CrossRef]

8. Rousseau, I.A.; Xie, T. Shape memory epoxy: Composition, structure, properties and shape memory performances. J. Mater. Chem. 2010, 20, 3431-3441. [CrossRef]

9. Korolev, A.; Mishnev, M.; Zherebtsov, D.; Vatin, N.I.; Karelina, M. Polymers under Load and Heating Deformability: Modelling and Predicting. Polymers 2021, 13, 428. [CrossRef] [PubMed]

10. Zhang, C.; Hankett, J.; Chen, Z. Molecular-level Understanding of Adhesion Mechanisms at the Epoxy/Polymer Interphases. ACS Appl. Mater. Interphases 2012, 4, 3730-3737. [CrossRef]

11. Kuksenko, V.S.; Ovchinnikov, V.A.; Slutsker, A.I. Elasticity of the intercrystallite zones and the mechanical properties of oriented polymers. Polym. Mech. 1969, 5, 891-895. [CrossRef]

12. Miller, R.; Ferri, J.K.; Javadi, A.; Krägel, J.; Mucic, N.; Wüstneck, R. Rheology of interfacial layers. Colloid Polym. Sci. 2010, 288, 937-950. [CrossRef]

13. Solar, M.; Qin, Z.; Buehler, M.J. Molecular mechanics and performance of crosslinked amorphous polymer adhesives. J. Mater. Res. 2014, 29, 1077-1085. [CrossRef]

14. Arzhakov, M. Relaxation in Physical and Mechanical Behavior of Polymers, 1st ed.; CRC Press: Boca Raton, FL, USA, 2019. [CrossRef]

15. Green, A.E.; Naghdi, P.M. Thermoelasticity without energy dissipation. J. Elast. 1993, 31, 189-208. [CrossRef]

16. Jensen, M.; Jakobsen, J. Effect of cure cycle on enthalpy relaxation and post shrinkage in neat epoxy and epoxy composites. J. Non-Cryst. Solids 2016, 452, 109-113. [CrossRef]

17. Rouxhet, P.G.; Doren, A.; Dewez, J.L.; Heuschling, O. Chemical composition and physico-chemical properties of polymer surfaces. Prog. Org. Coat. 1993, 22, 327-344. [CrossRef]

18. Lodge, T.P.; Muthukumar, M. Physical Chemistry of Polymers: Entropy, Interactions, and Dynamics. J. Phys. Chem. 1996, 100, 13275-13292. [CrossRef]

19. Pepicelli, M.; Jaensson, N.; Tregouët, C.; Schroyen, B.; Alicke, A.; Tervoort, T.; Monteux, C.; Vermant, J. Surface viscoelasticity in model polymer multilayers: From planar interfaces to rising bubbles. J. Rheol. 2019, 63, 815-828. [CrossRef]

20. Lu, H.; Wang, X.; Xing, Z.; Fu, Y.Q. A cooperative domain model for multiple phase transitions and complex conformational relaxations in polymers with shape memory effect. J. Phys. D Appl. Phys. 2019, 52, 1361-6463. [CrossRef]

21. Johnsen, J.; Clausen, A.H.; Grytten, F.; Benallal, A.; Hopperstad, O.S. A thermo-elasto-viscoplastic constitutive model for polymers. J. Mech. Phys. Solids 2019, 124, 681-701. [CrossRef]

22. Liu, W.; Zhang, L. Mechanisms of the complex thermo-mechanical behavior of polymer glass across a wide range of temperature variations. Polymers 2018, 10, 1153. [CrossRef]

23. Shaw, M.T.; MacKnight, W.J. Introduction to Polymer Viscoelasticity, 3rd ed.; Wiley Blackwell: Hoboken, NJ, USA, 2005. [CrossRef]

24. Sogolova, T.I.; Demina, M.I. Temperature dependence of the mechanical properties of polymers of different chemical structure in the temperature range from 4.2 to $300^{\circ} \mathrm{K}$. Polym. Mech. 1977, 13, 333-337. [CrossRef]

25. Moroz, J.D.; Nelson, P. Entropic elasticity of twist-storing polymers. Macromolecules 1998, 31, 6333-6347. [CrossRef]

26. Zhang, X.; Wen, H.; Wu, Y. Computational Thermomechanical Properties of Silica-Epoxy Nanocomposites by Molecular Dynamic Simulation. Polymers 2017, 9, 430. [CrossRef]

27. Gol'dman, A.Y.; Murzakhanov, G.K.; Soshina, O.A. Temperature-time analogy for thermorheologically complex polymeric materials. 1. Mixtures of partially crystalline polymers with elastomers. Polym. Mech. 1977, 13, 516-522. [CrossRef]

28. Chen, J.; Liu, L.; Fei, F.; Wang, Y.; Liu, Y.; Leng, J. Modeling mechanical behavior of epoxy-shape memory polymers. In Behavior and Mechanics of Multifunctional Materials and Composites, Proceedings of the SPIE, San Diego, CA, USA, 10-14 March 2013; International Society for Optics and Photonics: Bellingham, WA, USA, 2013. [CrossRef]

29. Khan, A.S.; Lopez-Pamies, O.; Kazmi, R. Thermo-mechanical large deformation response and constitutive modeling of viscoelastic polymers over a wide range of strain rates and temperatures. Int. J. Plast. 2006, 22, 581-601. [CrossRef]

30. Cheng, H.L.; Wang, J.; Huang, Z.P. A thermo-viscoelastic constitutive model for compressible amorphous polymers. Mech. Time-Depend. Mater. 2010, 14, 261-275. [CrossRef]

31. Lexcellent, C.; Butaud, P.; Foltête, E.; Ouisse, M. A Review of Shape Memory Polymers Thermomechanical Modelling: Analysis in the Frequency Domain. In Advances in Shape Memory Materials; Sun, Q., Matsui, R., Takeda, K., Pieczyska, E., Eds.; Springer: Berlin, Germany, 2017; Volume 73, pp. 57-80. [CrossRef]

32. Shenogina, N.B.; Tsige, M.; Patnaik, S.S.; Mukhopadhyay, S.M. Molecular Modeling Approach to Prediction of Thermo-Mechanical Behavior of Thermoset Polymer Networks. Macromolecules 2012, 45, 5307-5315. [CrossRef]

33. Lu, H.; Huang, W.M. On the origin of the Vogel-Fulcher-Tammann law in the thermo-responsive shape memory effect of amorphous polymers. Smart Mater. Struct. 2013, 22, 105021. [CrossRef]

34. Lu, H.; Leng, J.; Du, S. A Phenomenological Approach for the Chemo-Responsive Shape Memory Effect in Amorphous Polymers. Soft Matter 2013, 9, 3851-3858. [CrossRef]

35. Russian State Standard GOST 25.604-82 Design Calculation and Strength Testings. Methods of Mechanical Testing of Polymeric Composite Materials. Test for Bending Properties at Normal, Elevated, and Low Temperatures. Available online: https: / / docs.cntd.ru/document/1200012862 (accessed on 25 November 2021). 
36. Horta Muoz, S.; Serna Moreno, M.C. Multiaxial stress and strain analysis on laminated plates under different flexural loading rates. In Proceedings of the IOP Conference Series: Materials Science and Engineering, Roskilde, Denmark, 7-10 September 2020. [CrossRef]

37. Serna Moreno, M.C.; Romero Gutiérrez, A.; Martínez Vicente, J.L. Different response under tension and compression of unidirectional carbon fibre laminates in a three-point bending test. Compos. Struct. 2016, 136, 706-711. [CrossRef] 